How to Cite

Toirac, I. C. (2020). Physical-cognitive-emotional pedagogical integration approach for attention to diversity from initial training in physical culture. International Journal of Physics \& Mathematics, 3(1), 13-17. https://doi.org/10.31295/ijpm.v3n1.138

\title{
Physical-Cognitive-Emotional Pedagogical Integration Approach for Attention to Diversity from Initial Training in Physical Culture
}

\author{
Idalia Clejel Toirac \\ Universidad de Oriente, Facultad de Cultura Física Santiago de Cuba, Cuba \\ Corresponding authoremail: iclejel@uo.edu.cu
}

\begin{abstract}
The research is based on an approach of physical-cognitive-emotional pedagogical integration for the attention to diversity in initial training gives an account of how to structure this process based on equality between the physical-cognitive - Emotional and attention to diversity as aspects that typify the dynamics of pedagogy in the act of preparing for the improvement of educational practice.

Keywords---educational practice, pedagogical integration, physical culture, physical-cognitive, physical-cognitiveemotional.
\end{abstract}

\section{Introduction}

The term approach according to, (Silva, 2017) refers to the peculiar way in which a particular issue or difficulty is treated and how to reach a solution, fulfilling its objective. Other authors consulted as (Savin, 1962); (González, 1995); (Márquez, 2000); (Fuentes, 2000); (Âlvarez de Zayas, 2001); (Cruz, 2001); they consider that the term approach from an integrative conception makes it possible to organize and systematize in the educational teaching activity the integration of knowledge, habits, and experiences, through actions that generate learning and treatment to the student's modes of action. From these conceptions, it can be determined that this approach should work systematically by adjusting the process of attention to diversity from the initial training in the Physical Culture, to the physical, cognitive and emotional activity of those involved in the educational teaching process. Enabling a sociocultural connotation according to the needs that these students present before a socio-professional problem in the field of Physical Culture, which will be conditioned by a set of distinctive qualities and skills of the specialty in this type of educational community, but also to other customs that legitimize their daily educational practice (Roediger III \& Pyc, 2012; Paraskeva et al., 2008).

\section{Materials and Methods}

The modeling is of this integral approach expresses the alternative methodological direction to structure such training and has based on the concept of physical-cognitive-emotional pedagogical integration in Physical Culture (Liu, 2011; Hennessy et al., 2007). This direction has structured from a pedagogical model that must take into account the relevant paradigms of an initial formation energized by the various events caused in the processes of Physical Culture, the need for the cultural and constant impact of knowledge.

\section{Analysis and Discussion of the Results}

It has hoped that by pedagogically integrating the physical, cognitive, emotional, for the attention to diversity in the initial training, it can be tried to solve it correctly by teaching, about the specific point of attention to diversity in Physical Culture. Coexisting with the particularities of this approach means the possibility of giving attention to the

ISSN 2632-9417

Submitted: March 27, 2020 / Revised: April 09, 2020 / Accepted: May 18, 2020 
diversity in the initial formation of the Physical Culture, seen in pedagogical terms, by the physical-cognitiveemotional distinction in the training of students. Which have formed in an integrality from mental and physical activity, the mobilization of physical efforts, the use of emotional reserves in the face of extreme muscle movements and the unification of different fields: cognitive-affective, motor, and attitude, from the formation of the personality of these students of Physical Culture.

It constitutes a system formed by the integration of the praxis of Physical Culture and the results of learning in the position of (what has formed?). These are diversely summarized as cognitive, physical, and emotional. The steps in learning (how do you learn?) It learn in the activity and as a result, it is productive because it adapts to the content received according to practical reality; The context of learning is according to the spheres of action in the Physical Culture, according to the processes, expected contents, is contextualized, which take place according to the surrounding reality. Recognizing that this student can receive their educational practice, from the appropriation of knowledge, with a sociocultural nature that allows them to transform the professional culture of the educational community and to that same extent improve the process of attention to diversity around the objectives to have achieved in the aforementioned formative context. This approach has manifested from a comparative analysis of the initial training model of the Bachelor in Physical Culture and that of other careers for the determination of the level of correspondence established in the dynamics of pedagogical work and the demands of the sphere of action. It has presented from the articulating components shown in figure 1.

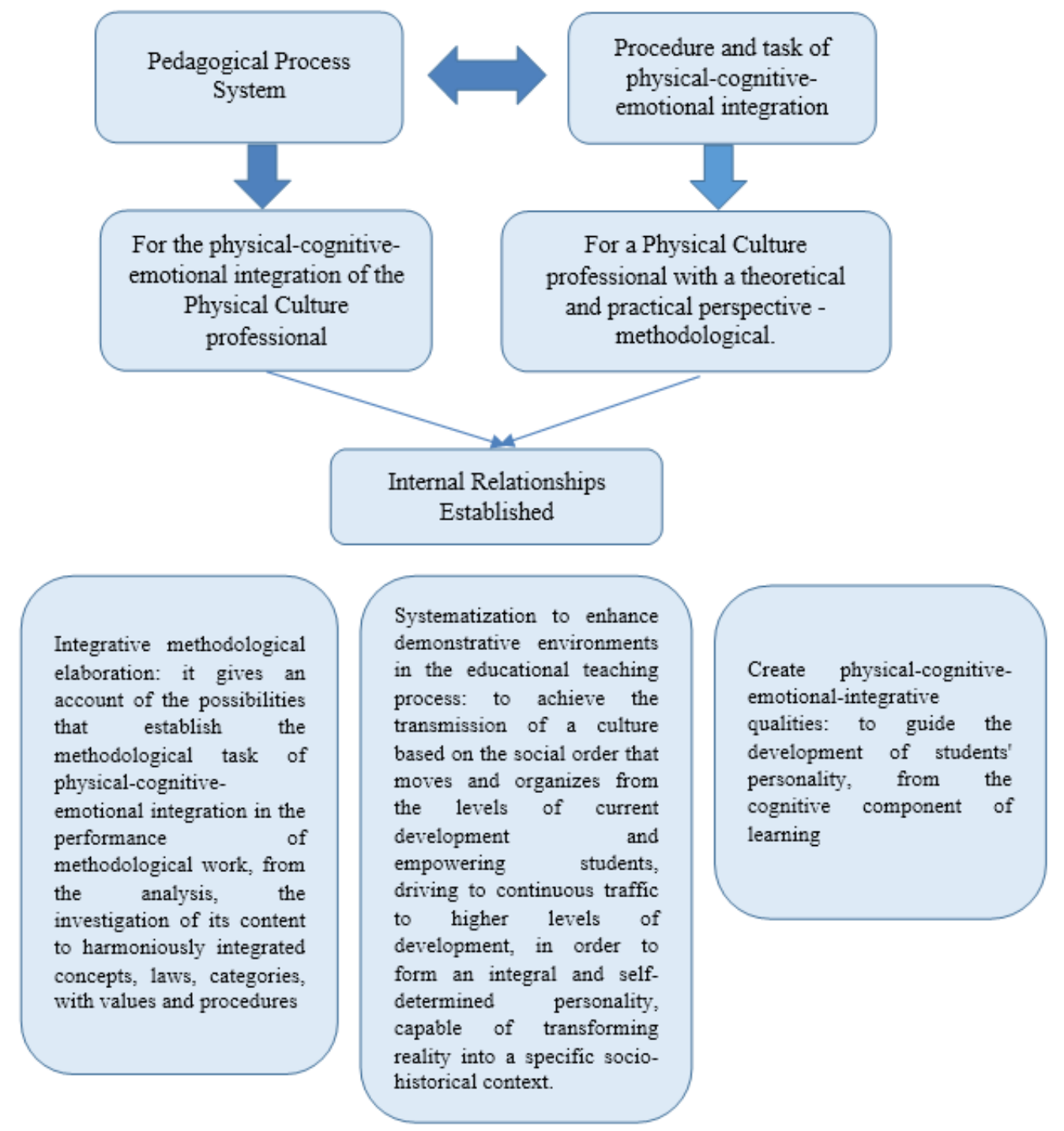

Figure 1. Articulating components 
In these internal relationships, the position given by (Silva, 2017) has assumed, regarding the link of integration and diversity. Since they have conditioned by the dynamics of methodological work as a whole.

Where integration: is that which exists in a single group, with a single purpose, a purpose, a common goal for all who participate in it.

And the attention to diversity: the multiplicity of all the subjects that deserve to be respected, their beliefs, their aptitudes, motivations, diversity of physical performance, the diversity in their sports preparation, diversity of sociocultural contexts in which it develops, different curricular approaches, manifest individual differences between the levels of student development, differences in the professional training of teachers. The diverse in the subjects, in the cognitive, in the emotional, in the methods. In essence, these relationships account for individual learning and exchange with that diversity.

This approach has the peculiarities to consolidate the physical, cognitive and emotional aspects of this pedagogical integration. This centralizes the teaching process by studying the possibility of the physical abilities and abilities that each student will have to raise a student independent of their functions through collaboration. Where they foster their interest and degree of participation and personal involvement in the learning tasks about physical development, using all the resources available in his personality to those provided by the group, involving the student himself in the construction of the most favorable conditions for the cognitive process.

It is from this context that the physical-cognitive has integrated, depending on the process of individual achievement of each student, where the capacity cognitive places the focus on the active, transformative, conscious subject, oriented towards an objective in interaction with others students and their actions for the purpose, using various means in certain socio-historical conditions. Teaching from the conception of learning and under scientific budgets has been characterized by being a developer.

But this cognitive intent according to the most current conceptions since physical learning has to be based largely on variability understood as the variation of the conditions of practice adapted to the evolutionary conditions so that, through these variations, during your movement you have you adapt your response and make decisions. With an integrality, variability, and diversity from these different physical-cognitive categories that must be given as a unit in the educational process to achieve a greater contribution to the Physical Culture to the global formation of personality, using physical-sports activities. When integrating the physical-cognitive must be from the own scientific and pedagogical preparation that each student achieves. Where the deployment of the process of rediscovery and reconstruction of knowledge by the student is allowed, taking into account their particularities, skills, and physical abilities, all It must allow an environment of cooperation and understanding between that physical-cognitive activity and the emotional state of the student.

The transcendence when understanding from the methodological point of view, the physical-cognitive-emotional unification as it allows an integral and diverse vision of the subjects as people and as social beings, has a fundamental premise to importance to the student as an active, constructive subject of their learning taking into account. The students are different that not everyone has the same learning pace or the same level of physical development due to multiple factors (size, body weight, muscle strength), while others require of systematic observation and the use of scientific methods, techniques, and instruments, and this identifies the emotional state of a student. Characterized by individual differences, which adversely affects the weakest or delays the development of the most advantageous from the physical Cognitive and emotional ( $\mathrm{Ng}$ et al., 2015; Sutin et al., 2015; Jack et al., 2013).

It is then that the emotional system from the (inspirations, attitudes, passions, and reflections) that are at the base of the student's behavior regarding the logic of new learning, allowing the development of skills, abilities, and skills that connote the emotion towards the physical activity, defining an active, critical, creative professional exercise because of the Physical Culture perspective. It can have expressed from the physical-cognitive-emotional integration through a commitment to the profession, which is interpreted as an emotional synthesis that articulates the ethical position of the student before their professional tasks of a pedagogical nature with their positive feelings and the development of instrumental resources, positively connoting the appropriation of cognitive-emotional physical integration.

The cognitive-emotional physical integration ensures the development process from these three integral components and from which this student develops in his framework of action that has constituted by an attitudinal aspect, referred to the valuation perception that the student has of himself. As well as a physical-cognitive-emotional aspect, due to the wide range of concepts that form the image of oneself concerning the lessons learned about the career, as well as the awareness of their changes and the safety of their actions in this sense. This integration has identified by the design and execution of pedagogical experiences to raise awareness. Their professional activity; elaboration, application, and evaluation of research instruments that allow him to diagnose and interpret the state of 
the identified pedagogical problem and develop actions based on the needs detected and from the understanding, captured by the student, to motivate, sensitize and familiarize them with the essentials of his professional role.

To explain it, we start from the procedures that articulate it, with original proposals, from participatory techniques or other actions that allow an integral vision of the Physical Culture. This will not be focused on the physical movement, on the person or the subject its motor action, acts and engages in a physical-sports activity while recreating and developing relationships with its peers, helping to create a climate of trust and cordiality that sets in motion the realization of exercises for training skills related to divergent thinking (fluency, flexibility, originality).

From integrality in the educational reality for the transformation of the socio-educational community, it fully develops the student (theoretical, practical, from cooperation and personal satisfaction, arouses the improvement of its functions (guiding, creative and investigative), based on the relationships established between intentionality and openness to new experiences; flexibility and methodological indication; subordination and methodological independence.

In this way, the pedagogical professional group can thus begin to walk the path of tolerance to inaccuracy, as a necessary element to produce creative responses. It is about respecting the time and rhythm required by each student in the socio-educational community, to prepare, analyze, to assess, or issue a criterion or suggestion, that is to say, keep in mind that one works with psychic singularities. With bearers of a story, of a belief, with subjects of desires, motives, and intellection, therefore, also have varying amounts of anguish, depending on the importance of inhibited desires that can block their productions in different phases of the creative process. Its integral perspective has evidenced in the relationship of the integration approach with the self-preparation and preparation that the student receives from the Physical Culture and with the alternative of the socio-educational community. Which has been reached, because of the diagnosis, to achieve a synthesis of needs, interests, problems, and potentialities, in the context of methodological work; also, it allows us to understand the dialectical relationships that occur as a totalizing process. From the previous approaches, it is possible to recognize that the approach allows understanding and systematizing the interrelation of all the theoretical, methodological, and practical components, which occur within the focus of integrality in the educational reality for the transformation of the socio-educational community of the Physical Culture student.

\section{Conclusions}

These reasons justify the need for the physical-cognitive-emotional pedagogical integration approach that is specified in the particularities of the initial training aimed at students of Physical Culture by recovering and structuring those training processes of an abstract and decontextualized nature that do not respond coherently to the needs of the student of Physical Culture.

\section{References}

Álvarez de Zayas, R.M. (2001). Cuba. Towards a comprehensive and contextualized curriculum [Material in electronic support], pp. 19-20: Enrique José Varona Higher Pedagogical Institute.

Cruz, S. (2001). Havana. Programs and Methodological Orientations of Physical Education (first to ninth grade): Editorial People and Education.

Fuentes, H. (2000). Cuba. Integral approach to professional training for the challenges of the 21st Century: On CDR. Memories of the Provincial Event: Pedagogy.

González, F. (1995) Argentina. Teaching the way of teaching. Readpsychology, p.8: Buenos Aires Library.

Hennessy, S., Wishart, J., Whitelock, D., Deaney, R., Brawn, R., La Velle, L., ... \& Winterbottom, M. (2007). Pedagogical approaches for technology-integrated science teaching. Computers \& Education, 48(1), 137-152. https://doi.org/10.1016/j.compedu.2006.02.004

Jack, A. I., Dawson, A. J., Begany, K. L., Leckie, R. L., Barry, K. P., Ciccia, A. H., \& Snyder, A. Z. (2013). fMRI reveals reciprocal inhibition between social and physical cognitive domains. Neurolmage, 66, 385-401. https://doi.org/10.1016/j.neuroimage.2012.10.061

Liu, S. H. (2011). Factors related to pedagogical beliefs of teachers and technology integration. Computers \& Education, 56(4), 1012-1022. https://doi.org/10.1016/j.compedu.2010.12.001

Márquez, A. (2000). Santiago de Cuba. Initial research training at the University of Pedagogical Sciences: CD-R. Memories of the Provincial Event: Pedagogía 
Ng, T. P., Feng, L., Nyunt, M. S. Z., Feng, L., Niti, M., Tan, B. Y., ... \& Yap, K. B. (2015). Nutritional, physical, cognitive, and combination interventions and frailty reversal among older adults: a randomized controlled trial. The American journal of medicine, 128(11), 1225-1236. https://doi.org/10.1016/j.amjmed.2015.06.017

Paraskeva, F., Bouta, H., \& Papagianni, A. (2008). Individual characteristics and computer self-efficacy in secondary education teachers to integrate technology in educational practice. Computers \& Education, 50(3), 1084-1091. https://doi.org/10.1016/j.compedu.2006.10.006

Roediger III, H. L., \& Pyc, M. A. (2012). Inexpensive techniques to improve education: Applying cognitive psychology to enhance educational practice. Journal of Applied Research in Memory and Cognition, 1(4), 242248. https://doi.org/10.1016/j.jarmac.2012.09.002

Sanchez, P. K. M., Lopez, C. G. N., Lopez, M. M. L., \& Figueroa, Y. G. M. (2019). Learning problems: pedagogical intervention. International research journal of engineering, IT \& scientific research,5(6), 25-32. https://doi.org/10.21744/irjeis.v5n6.806

Savin, N.V. (1962). The teaching methodology. I take I and II. [Material in electronic support], pp. 29-34: Enrique José Varona Higher Pedagogical Institute.

Silva, J.N. (2017). Cuba. Methodology for the formation of sports identity from physical education in basic secondary school. Thesis in option to the scientific degree of Doctor of Physical Culture Sciences: University of Camagüey

Sutin, A. R., Stephan, Y., Carretta, H., \& Terracciano, A. (2015). Perceived discrimination and physical, cognitive, and emotional health in older adulthood. The American Journal of Geriatric Psychiatry,23(2), 171-179. https://doi.org/10.1016/j.jagp.2014.03.007 